\title{
The Great American Outdoors Act of 2020: a Tool for Improving Urban Health and Health Equity
}

\author{
Kenneth W. Kizer iD
}

Accepted: 18 November 2020/ Published online:8 January 2021

(C) The New York Academy of Medicine 2021

The Great American Outdoors Act (GAOA or Act) [1] was signed into law on August 4, 2020, culminating a rare instance of bipartisanship in the highly polarized 116th Congress and unlikely Trump Administration support for an environmental initiative. Hailed by supporters as the most significant conservation legislation in many decades, the Act is also a win for urban health and health equity.

More than $80 \%$ of the US population lives in urban areas, and exposure to green space and participation in nature-based activities are important determinants of health for urban dwellers [2, 3]. Green space is a loosely defined term referring to land that is partly or completely covered with grass, trees, shrubs, or other vegetation, often with some form of flowing or standing water, and includes wildlands and nature reserves, parks, community gardens, and play grounds or sports playing fields [4].

Access to green space is limited for many urbanites, especially low-income families. According to The Trust for Public Land, 100 million Americans, including 28 million children, do not have ready access to parks in their neighborhoods (https://www.tpl.org/parkscore). Diminished exposure to green space is associated with multiple adverse health consequences, including higher all-cause mortality and increased rates of obesity, cardiovascular disease, and mental illness [2, 3, 5-8]. The

K. W. Kizer $(\bowtie)$

Atlas Research, LLC, 805 15th Street, NW, Suite 910,

Washington, DC 20005, USA

e-mail: kwkizer@atlasresearch.us
GAOA provides a means to improve this health determinant.

The GAOA was originally introduced in the House of Representatives in 2019 by the late Congressman John Lewis, but the legislation was later re-purposed. It was re-introduced in the Senate in March 2020, where it quickly garnered 59 co-sponsors and broad support from environmental, conservation, and consumer groups and the US Chamber of Commerce but seemed to be little noticed by the health sector during its legislative course. It passed both the Senate and House with wide margins despite opposition from livestock, mining, and other natural resource use interests.

The GAOA is a major win for conservation because it permanently finances the Land and Water Conservation Fund and provides funding to materially reduce the deferred maintenance backlog at national parks and other federal wildlands, both of which can benefit population health by facilitating access to green space and nature-based activities.

The Land and Water Conservation Fund (LWCF) has long been the crown jewel of publicly funded conservation programs. Established in 1964 for 25 years and reauthorized for another 25 years in 1989, the LWCF provides funds to federal, state, and local governments to acquire, maintain, or enhance outdoor lands for recreational purposes and to protect and conserve natural lands as parks, protected forests, and wildlife reserves. Every state and nearly every county in the USA have benefited from the LWCF, which has funded projects ranging from development of large outdoor recreation areas like Harper's Ferry in West Virginia, Big Sur in 
California, and the Greater Yellowstone Ecosystem in Montana to the establishment of myriad local parks and playgrounds, sports playing fields, and community walking trails.

The LWCF has always struggled for funding. Its primary source of funds has been fees and royalties from offshore oil and gas drilling, and while authorized for up to $\$ 900$ million per year, Congress has usually diverted most of the source funds to other purposes. The LWCF expired in 2018 but was resurrected and permanently reauthorized, but not funded, as part of the John D. Dingell, Jr. Conservation, Management, and Recreation Act of 2019 [9]. The GAOA finances the LWCF at $\$ 900$ million per year in perpetuity.

The GAOA also creates a new National Park and Public Lands Legacy Restoration Fund that provides $\$ 9.5$ billion over the next 5 years to complete deferred maintenance projects in national parks and forests, federal wildlife refuges, interstate hiking trails, and designated historic sites, monuments, and seashores [1]. The deferred maintenance backlog at the nation's chronically underfunded national parks has grown to nearly $\$ 12$ billion in recent years, adversely affecting their esthetics, usability, and safety. The backlog includes hundreds of unfunded projects for repair or replacement of deteriorating roads and bridges, aging buildings and water systems, poorly maintained hiking trails, and neglected campgrounds.

This new special fund will receive an amount equal to $50 \%$ of all federal revenues from development of oil, gas, coal, or renewable energy on federally controlled lands and waters. These funds will be used to finance priority maintenance projects of the National Park Service (NPS) and four other federal agencies, with the NPS receiving $70 \%$ of the funds (an additional $\$ 6.65$ billion over the next 5 years). The law also authorizes philanthropic cash or in-kind donations to the Fund, which may be used to reduce the NPS maintenance backlog or to support public-private partnerships that may significantly leverage public funds.

The belief that exposure to nature and health are connected dates to antiquity and has long influenced urban planning, leading to the establishment of parks and tree-lined neighborhoods in many cities, although these areas often have not been accessible to lowincome persons. Despite the long history of the belief that health and exposure to nature are connected, research-based evidence affirming this connection has accrued only in recent years. For example, studies in the 1980s and 1990s showed that hospitalized patients exposed to plants, gardens, or images of nature resulted in fewer post-surgical complications, less need for pain medication, less anxiety, faster healing, and shorter hospital stays, among other benefits. $[10,11]$

Research has more recently established a clear connection between green space and population health broadly. Although difficult to separate from the effects of socioeconomic status, accumulating evidence shows that residents of communities having easily accessible and safe parks or other green spaces, independent of other factors, have reduced all-cause mortality and lower rates of obesity, cardiovascular disease, and type 2 diabetes; probably improved pregnancy outcomes; and improved mental health [2, 3, 5-8].

Exposure to green space is particularly connected with mental health benefits and offers the potential to significantly improve the mental health of many lowincome neighborhoods with relatively small investments. For example, simply converting environmentally blighted urban spaces to green spaces without changing other circumstances can materially improve mental health, feelings of well-being, and community resilience $[3,12]$. Exposure to green space may be especially important to the mental health of children and young adults. A study of the Danish population found that higher levels of exposure to green space during childhood was associated with significantly lower risks of multiple psychiatric disorders later in life, independent of socioeconomic factors, parental age or history of mental illness, and degree of urbanization [13]. The association was stronger for greater cumulative exposure to green space, suggesting a dose-response relationship. Similarly, a recent review of the literature found that as little as 10-20 min of sitting or walking in various natural settings positively affected a wide array of psychological and physiological markers of well-being among college students [14].

Research has begun to elucidate the multiple interrelated and possibly synergistic biopsychosocial factors that contribute to observed green health benefits. These factors include increased physical activity, reduced stress, enhanced immune function, increased social cohesion, and reduced exposure to anthropogenic environmental hazards such as air and noise pollution and heat [2, 3, 5-7]. More research is needed to determine the specific physiological mechanisms responsible for the observed benefits.

Exposure to green spaces also may increase the risk of some adverse health effects, including increased 
exposure to allergens, air pollutants, pesticides, herbicides, and ultraviolet radiation; transmission of arthropod-borne or zoonotic infectious diseases; and the occurrence of criminal acts and accidental injuries $[2,3]$. However, proper design and maintenance of parks and other urban green spaces can effectively minimize the risks of untoward health effects.

Interestingly, enactment of the GAOA can be attributed in significant part to the COVID-19 pandemic and associated socioeconomic and political dynamics. The economies of several Western states are substantially linked to national park tourism and outdoor recreation on federal lands. Many gateway communities around the national parks have suffered due to pandemic-related decreased tourism. The Act gained broad political support because it promises to create more than 100,000 new jobs (e.g., to repair park infrastructure) and bring financial relief to these communities. Additionally, because of pandemic-related restrictions on other forms of recreation and the relative greater safety of outdoor activities, record numbers of Americans are rediscovering the outdoors, particularly through local and state parks. On seeing the often-deteriorated condition of these sites, many park visitors have called on Congressional and other elected representatives to fund their restoration and improved maintenance.

Exposure to green space and participation in naturebased activities are important determinants of health, especially for urban dwellers. Given the large number of people whose health and sense of well-being could be improved by relatively low-cost green interventions, increasing urban green space should be a prominent population health improvement strategy, particularly for low-income urban neighborhoods where green space is too often uncommon and obesity, diabetes, cardiovascular diseases, and mental health problems are too common. By providing ongoing funding for developing parks and other green space through the Land and Water Conservation Fund, the Great American Outdoors Act can be a significant tool for improving population health and promoting health equity.

\section{References}

1. Public Law No. 116-152. The Great American Outdoors Act of 2020.

2. WHO Regional Office for Europe. Urban green space interventions and health: a review of impacts and effectiveness.
Copenhagen: World Health Organization; 2017. https://www. euro.who.int/en/health-topics/environment-and-health/urbanhealth/publications/2017/urban-green-space-interventionsand-health-a-review-of-impacts-and-effectiveness.-fullreport-2017. Accessed 4 Nov 2020.

3. Hunter RF, Cleary A, Braubach M. Environmental, health and equity effects of urban green space interventions. In: Marselle MR, Stadler J, Korn H, Irvine KN, Bonn A, editors. Biodiversity and health in the face of climate change: Springer Open; 2019. p. 381-409. https://doi.org/10.1007 /978-3-030-02318-8_17.

4. Taylor L, Hochuli DF. Defining greenspace: multiple uses across multiple disciplines. Land Urb Plan. 2017;158:2538. https://doi.org/10.1016/j.landurbplan.2016.09.024.

5. Zupancic T, Westmacott C, Bulthuis M. The impact of green space on health and air pollution in urban communities: a meta-narrative systematic review. Vancouver: David Suzuki Foundation; 2015. Available at: https://davidsuzuki.org/wpcontent/uploads/2017/09/impact-green-space-heat-airpollution-urban-communities.pdf. Accessed 4 Oct 2020.

6. Rojas-Rueda D, Nieuwenheijsen MJ, Gascon M, Perez-Leon D, Mudu P. Green spaces and mortality: a systematic review and meta-analysis of cohort studies. Lancet. 2019;3(11):e469 77. https://doi.org/10.1016/S2542-5196(19)30215-3.

7. Kondo MC, Fluehr JM, McKeon T, Branas CC. Urban green space and its impact on human health. Intl J Environ Res Public Health. 2018;15(3):445. 1-28. https://doi. org/10.3390/ijerph15030445.

8. Yang BY, Hu LW, Jalaludin B, Knibbs LD, Markevych I, Heinrich J, et al. Association between residential greenness, cardiometabolic disorders, and cardiovascular disease among adults in China. JAMA Netw Open. 2020;3(9):e2017507. https://doi.org/10.1001/jamanetworkopen.2020.17507.

9. Public Law No. 116-9. The John D. Dingall, Jr. Conservation, Management, and Recreation Act of 2019.

10. Grinde B, Patil GG. Biophilia: does visual contact with nature impact on health and well-being? Int J Environ Res Public Health. 2009;6:2332-43. https://doi.org/10.3390 /ijerph6092332.

11. Ulrich RS. View through a window may influence recovery from surgery. Science. 1984;224(4647):420-1.

12. South EC, Hohl BC, Kondo MC, MacDonald JM, Branas CC. Effect of greening vacant land on mental health of community-dwelling adults. A cluster randomized trial. JAMA Network Open. 2018;1(3):e180298. https://doi. org/10.1001/jamanetworkopen.2018.0298.

13. Engemann K, Pedersen CB, Arge L, Tsirogiannis C, Mortensen PB, Svenning JC. Residential green space in childhood is associated with lower risk of psychiatric disorders from adolescence into adulthood. PNAS. 2019;116(11): 5188-93. https://doi.org/10.1073/pnas.1807504116.

14. Meredith GR, Rakow DA, Eldermire ERB, Madsen CG, Shelley SP, Sachs NA. Minimum time dose in nature to positively impact the mental health of college-aged students, and how to measure it: a scoping review. Fron Psychol. 2020;10(2942) https://doi.org/10.3389/fpsyg.2019.02942.

Publisher's Note Springer Nature remains neutral with regard to jurisdictional claims in published maps and institutional affiliations. 